\title{
CAMPOS DE EXPERIÊNCIA PELA TEORIA DE VYGOTSKY
}

\author{
VANESSA TAKIGAMI ALVES*
}

\begin{abstract}
RESUMO
Este artigo tem por objetivo avançar nos estudos dos Campos de Experiência, estabelecida na Base Nacional Comum Curricular (BNCC), somado à prática do professor com a contribuição da teoria de Vygotsky. Trazemos a teoria histórico-cultural como concepção do fazer pedagógico aplicado aos Campos de Experiência. Houve um percurso histórico de compreensão do ser humano em sua aprendizagem; como ser essencialmente biológico, num trajeto natural de desenvolvimento; partindo para a compreensão de aprendizagem a partir das interações sociais, e que a aprendizagem gera desenvolvimento, no qual delineia o trabalho por Campos de Experiência na Educação Infantil. Concluímos que a escola tem enorme responsabilidade no desenvolvimento da criança, pois pode ser gerador das interações sociais, na medida em que seu papel, bem como a mediação do professor, são fundamentais na promoção da aprendizagem, e, portanto, na formação e evolução infantil.
\end{abstract}

Palavras-chave: Campos de Experiência, teoria histórico-cultural, aprendizagem.

* Aluna do Programa de Pós-graduação em Educação da Universidade Metodista de São Paulo (UMESP). 


\begin{abstract}
The aim of this article is to advance the Field of Experience studies, contained in the National Curricular Joint Base (BNCC), allied to the teacher 's practice with the contribution of Vygotsky' $s$ theory. We draw the historical cultural theory as a conception of the pedagogical practice applied to the Fields. The historical course of understanding the human being's learning, how to be essentially biological, in a natural course of development, to understand learning from social interactions, and that learning generates development, outlines the work by Fields of Experience in Education Child. We conclude that the school has a huge responsibility in the development of the child, the role of the school and the mediation of the teacher are fundamental elements in the promotion of learning, therefore, in the development of the child. Key Words: Fields of Experience, cultural historical theory, learning.
\end{abstract}

Este artigo tem por objetivo avançar na compreensão dos Campos de Experiência por intermédio da Base Nacional Comum Curricular - BNCC - (BRASIL, 2017) e da contribuição da teoria de Vygotsky para a prática do professor. Quando falamos de Campos de Experiência qual compreensão o professor precisa ter? Primeiro necessita entender de onde vem o conceito de Campos de Experiência, para que então possa ter clareza dessa concepção e aplicá-la à prática.

Consideraremos aqui que a BNCC (BRASIL, 2017) já compõe o percurso de estudo do leitor, partindo dele como um conhecimento prévio.

Quando pensamos em Campos de Experiência; necessariamente precisamos fazer uma desconstrução do conceito de prática docente de tempos atrás. Convidamos aqui para uma reflexão de qual Pedagogia estamos falando para entender tais Campos.

A nossa prática vem muito provavelmente de um período do século XX, de uma abordagem biologizante do termo biolo- 
gizar $^{1}$, que era uma teoria avançada para a época; por acreditar que o ser humano desenvolveria determinada aptidão; de acordo com o seu desenrolar/crescimento natural, biológico. Porém as teorias caminham para a reelaboração e daí então surge a teoria histórico-cultural, de Vygotsky, considerada histórica porque parte do princípio de que nascemos num tempo histórico; que condiciona a forma como somos e nascemos numa cultura, num conjunto de modos de pensar, de forma de agir, de valores e sentimentos que conforma quem somos. Isso significa que somos formados a partir das interações, como possibilidade de desenvolvimento para aprendizagem, não sendo o suficiente o crescimento natural biológico.

Essa teoria afirma justamente o contrário -, que vem da psicologia, e não é mais da abordagem biologizante. Por isso falamos da desconstrução da prática docente, pois olha a pessoa como um ser que precisa da mediação social para o desenvolvimento das funções psicológicas superiores, proporcionando aprendizagem. Só então o desenvolvimento será possível.

Na visão de Vygotsky (2007), embora o homem pertença à espécie humana, ele só é humanizado nas relações, isso quer dizer que dependemos do outro para nos humanizarmos. A relação com as pessoas vai determinar o rumo da inteligência e personalidade da criança. A teoria histórico-cultural, que tem suas origens nos estudos de Vygotsky (2007), inova na compreensão da criança como ser biológico - acreditava- se que a

Biologizar: reduzir as explicações da realidade à determinação biológica dos seus fenômenos, desconsiderando ou subordinando as demais instâncias (sociocultural, psicológica, econômica, política) aos princípios explicativos biológicos. O evolucionismo biológico do século XIX foi a principal influência para as explicações biologizantes, e teve grande impacto nos estudos sociológicos, antropológicos, e psicológicos no século XX. A perspectiva biologizante acabou por ser incorporada ao senso comum e continua a ser uma forma de argumentação presente em explicações científicas ou não. Disponível em: http://www.comfor.unifesp.br/wp-content/docs/ COMFOR/biblioteca_virtual/GDE/mod1/Glossario.pdf 
criança desenvolvia naturalmente a sua inteligência e sua personalidade à medida que crescia, ou seja, com o passar do tempo e sem necessidade de intervenção. Os cuidados seriam apenas para satisfazer as necessidades básicas para sua sobrevivência.

Já de acordo com a teoria histórico-cultural, tudo o que somos aprendemos ao longo da vida, na medida em que somos seres históricos culturais. Significa que não somos de determinada maneira porque "puxamos a alguém"; quer dizer inclusive que não nascemos predestinados, e é isso que dá sentido ao papel da escola, do professor. Não nascemos com um conjunto de instintos, embora a nossa genética seja sofisticada.

Nesse aspecto, diante da perspectiva da necessidade da mediação social para a formação do ser humano, este só se desenvolve pela aprendizagem e é justamente aí que se destaca o papel da escola e do professor. Podemos utilizar como exemplo da relevância da escola na vida das crianças, a história do menino lobo - garoto que sobreviveu na selva e conviveu com lobos e não aprendeu a falar a língua dos humanos; apenas a desses predadores. A linguagem é um exemplo de que o desenvolvimento não se deve a fator genético, visto que é aprendida, e considerando que essa aprendizagem impulsionará para a sua evolução, entendemos a importância das interações.

Para Vygotsky (OLIVEIRA, 1997) a relação pensamento e linguagem acontece à medida que comunicamos algo, mesmo que na ausência da fala, das palavras como comunicação. Podemos estabelecer a comunicação por intermédio de gestos e expressões para comunicar algo. Quando sorrimos passamos a mensagem que estamos abertos ao outro. Quando utilizamos de um tom rude de voz, "dizemos" que não estamos gostando de algo. Porém, a relação de pensamento e linguagem se desenvolve implicando uma compreensão generalizada do mundo.

\section{SIGNOS CONSTRUÍDOS PELA CULTURA}

E nessa compreensão de pensamento e linguagem encontramos a sua percepção do que são os signos para Vygotsky 
(OLIVEIRA, 1997): são construídos culturalmente. A língua, especificamente como fala, é o principal instrumento de representação simbólica de que os seres humanos dispõem e se difere de linguagens diversas. $\mathrm{Na}$ verdade, os signos diferenciam as linguagens. Sabe-se que a espécie animal tem capacidade de estabelecer uma forma de comunicação que difere da língua humana. Já o ser humano desenvolve a língua ao longo de seu crescimento. O bebê inicia utilizando a língua do choro como função comunicativa, além do reflexo de sentimentos de dor, fome e outros; mas a partir da relação com o outro ele entende que esse choro comunica algo e que cada tipo de choro transmite informação de condições diferentes.

E então, após essa primeira aquisição da língua do bebê, vem a segunda função da linguagem, que Vygotsky (2007) chamará de pensamento generalizante: quando a língua se encaixa com o pensamento. Nessa segunda função temos a capacidade de classificar as coisas por meio das palavras que nomeiam os objetos, nos dando a capacidade de abstrair, de generalizar, de classificar, o que se torna possível a partir do momento que dispomos de um sistema simbólico.

Segundo a pedagoga Marta Kohl de Oliveira (1997),

o significado de uma palavra representa um amálgama tão estreito do pensamento e da linguagem que fica difícil dizer se se trata de um fenômeno da fala ou do pensamento. Uma palavra sem significado é um som vazio; o significado, portanto, é um critério da 'palavra', seu componente indispensável. Pareceria, então, que o significado poderia ser visto como um fenômeno da fala. Mas, do ponto de vista da psicologia, o significado de cada palavra é uma generalização ou um conceito. E como as generalizações e os conceitos são inegavelmente atos de pensamento, podemos considerar o significado como um fenômeno do pensamento. (1997, p. 48).

Essa relação pensamento-linguagem é tipicamente humana, e mais uma vez vale ressaltar que se trata de uma condição da 
conexão com o outro para essa relação acontecer, para que a linguagem se desenvolva. Nos referimos aqui à segunda função social da linguagem, já que a primeira função social da linguagem (gestos, expressão, sons) pode se desenvolver independentemente da interação com o outro, no sentido da aquisição cultural.Essa primeira função social da linguagem é chamada; na Psicologia; de Inteligência Prática, por meio da qual claramente se chega a uma resolução - é chamada de Prática porque não se utiliza de componente simbólico, e sim no plano concreto. Essa Inteligência Prática é utilizada pelos bebês antes de adquirirem a linguagem como componente simbólico. Por exemplo, o bebê utiliza o recurso do choro para conseguir algo, antes de adquirir a linguagem, e após a aquisição do componente simbólico faz uso da palavra para conseguir esse algo além, pois entra a condição de negociação, da utilização de um recurso que não está concretamente exposto ao bebê. A aquisição da segunda função da linguagem acontece quando a criança passa da Inteligência Prática para a Inteligência Abstrata, que funciona em planos simbólicos. Aí então se torna capaz de imaginar, intentar, criar e recorrer a experiências passadas, que é de pensamento generalizante. Porém, essa passagem para a Inteligência Abstrata é necessário que o outro apresente essa linguagem, através da interação, na aquisição da cultura.

A partir do momento que cada palavra e a construção das frases vão dando sentido à criança é que podemos considerar fazer parte de sistema simbólico da criança. e então passa a articular pensamento e linguagem. Um exemplo da transição do concreto para o abstrato é quando a palavra é pronunciada, mas o seu sentido não está ligada ao pensamento, ao seu significado. Há associação da palavra colher para o objeto, somente, num primeiro momento. Já num segundo momento, a partir da interferência cultural por intermédio do outro, a função social da colher é internalizada e então a criança é capaz de aplicar o pensamento da palavra colher para planejar o seu uso numa 
relação mais complexa do que a conexão direta da palavra com o objeto. Fazendo então a relação da aquisição da linguagem por meio da interação, o foco está fortemente estabelecido nas brincadeiras, sendo esta a principal atividade da criança. Quando mencionamos a Inteligência Abstrata podemos percebê-la nas brincadeiras das crianças, especialmente naquelas de faz de conta, em que as crianças recorrem à imaginação - isso se torna possível quando o sistema simbólico é parte aquisitiva da criança. As brincadeiras devem ser vivenciadas, pois a imaginação não vem de fora para dentro, mas, ao contrário, a criança imagina a partir de uma necessidade, cria mecanismos de autocontrole, conduta, disciplina, regras, para entrar na fantasia. Por exemplo, quando brinca de ser mãe não pode se comportar como um bebê. É a concretização da comunicação por meio da significação.

Então a aprendizagem tem o poder de desenvolver. A BNCC organiza a aprendizagem das crianças a partir de 2 eixos estruturantes: as interações e brincadeiras e, uma vez que tanto as interações como as brincadeiras são proporcionadas na escola, com a intencionalidade de promover aprendizagem, podemos dizer que o papel da escola é desenvolvimento. A aprendizagem impulsiona desenvolvimento, razão pela qual o professor organize e planeja suas propostas, pensando em desenvolvimento, pensando quais as aprendizagens que vão promover esse desenvolvimento. O fim da educação não é a aprendizagem, mas o desenvolvimento, que certamente resultará na mudança de ótica do que era até então trabalhado na escola.

Precisamos de um professor de creche, como um professor intelectual, que tenha conhecimento do desenvolvimento da criança, das suas potencialidades, atuando com intencionalidade, tendo a função de mediador das experiências das crianças. Nesse ponto da análise recorremos novamente a Vygotsky (OLIVEIRA, 1997), para quem somos a única espécie que nasce com aptidões de adquirir aptidões. Com isso, o professor tem a missão de considerar todas as crianças capazes de aprender habilidades. 
Tais considerações nos permitem inferir que o ofício do professor pode ser entendido como missão só aumenta, quando também entendemos, a partir da teoria histórico cultural que a aprendizagem promove o desenvolvimento da inteligência e da personalidade. Significa que o professor é o sujeito que faz a mediação entre o conteúdo e o processo de aprendizagem. Esta é uma das importantes funções da educação.

Assim, chegamos a Formosinho (2007), que entende que quando damos aula as crianças são respondentes. A mediação na aquisição do conhecimento na Educação Infantil é também encargo do professor. E quando mediamos, proporcionamos experiências que resultam em aprendizagem a partir da intencionalidade na organização do ambiente, nos materiais oferecidos, inclusive na forma como são ofertados. Oportuno destacar que é fundamental a função do professor no planejamento das propostas via reflexão da prática obtida no encontro com as crianças. Nesse processo ele pode até mesmo lançar mão da documentação pedagógica, que é a comunicação dos registros do professor (que é aquilo que já aconteceu), pois tal medida possibilita indicar ações futuras. Entende-se que esse planejamento pode ser igualmente feito a partir da observação de um desenho, de uma brincadeira, do que os garotos e garotas estão falando, como se comunicam. Em suas atividades o professor deve despertar nas crianças o encantamento pelo aprendizado. O professor precisa ter como propósito a Intervenção Pedagógica, que é a relação intencional do outro, de um profissional da educação trazendo a importância desse mundo humano, dessa cultura, do outro social. O professor precisa ser mediador nessa relação, considerando a criança um ser ativo e protagonista da sua história. Caso contrário, se a sua atuação for de um professor de transmissor de conhecimento, impossibilitará das crianças pensarem por si e desenvolverem suas hipóteses a partir das suas experiências. É a intencionalidade do professor que determinará as qualidades das experiências vividas pelas crianças, sendo primordial para a 
sua aprendizagem promover o desenvolvimento da inteligência e da personalidade.

Entendemos que o ser humano, ao nascer num determinado período da história, bem como num lugar específico, vai construindo seu registro histórico-cultural e certamente é afetado pela cultura local e pelo seu relacionamento com os outros seres. Tudo isso terá forte influência no desenvolvimento de todos nós. A cultura contém qualidades humanas, sendo a escola um lugar favorável e propício para garantir às crianças acessarem a cultura mais elaborada.Quando penso em Campos de Experiência, entendo que o pensamento fragmentado não existe e que não é possível trabalhar somente linguagem oral, ou matemática, ou ciências e natureza, pois na cabeça da criança é tudo junto e misturado, nós é que separamos em caixinhas. É necessário oferecer às crianças a cultura que a humanidade produz, a arte e a ciência. É a herança da humanidade; o que as gerações anteriores deixaram de herança para a nossa cultura e o que eu estou deixando para as que aqui já estão e as que virão.Quando penso que o que estou trazendo para a escola é a cultura... ao invés de eu olhar para a língua portuguesa como um instrumento escolarizado de decodificação de letras que se juntam e viram palavras, que viram frases devo olhar como uma produção do homem com o intuito de se comunicar, de se expressar, de dizer alguma coisa para o outro, de fazer o registro de sua história. E qual o sentido dessa escrita para a humanidade? Então trazemos a vida real, as práticas sociais para a escola, trazemos a cultura como prática social e não como escolarização. Se não entendo isso, os Campos de Experiência permanecem como áreas de conhecimento.

\section{CONHECIMENTO QUE VEM DAS RELAÇÕES}

Antes a lógica estava no conteúdo. Hoje ela está nas práticas sociais, nos Campos de Experiência em conexão. E quando nos referimos a essa relação com o outro que proporciona aprendizagem para a criança não estamos falando de qualquer 
relação. Vygotsky é um teórico que assegura grande contribuição para a educação e a sua teoria percorre dentro das escolas, fomenta debates e garante argumentos a quem se preocupa com as intervenções pedagógicas do professor que age diretamente no desenvolvimento da criança.

Este autor é considerado um teórico interacionista, pois leva em conta que o funcionamento psicológico não está previamente pronto, não nasce com a pessoa - ele é recebido por intermédio do outro numa construção a partir das relações; vem do ambiente e do sujeito ativo. O desenvolvimento não é natural, mas sim fruto das experiências vividas. Nesse contexto, há que se considerar que a aprendizagem depende de a criança estar completamente envolvida, com o corpo, com a mente, com a emoção. Significa passar por uma experiência plena para essa aprendizagem qualificada. Tal envolvimento pode ser comparado a quando lemos sobre determinada questão: como, por exemplo, o método de mistura de cores para resultar em outra cor. Quando essa experiência é vivida, especialmente por uma necessidade dada, a aprendizagem é outra, de fato. É aprendizagem no processo de apropriação.

A postulação interacionista se apoia nos planos genéticos desenvolvidos por Vygotsky (1996), considerando quatro entradas de desenvolvimento que juntas caracterizavam o funcionamento psicológico do ser humano: a filogênese, a ontogênese, a sociogênese e a microgênese.

A filogênese diz respeito à nossa história enquanto espécie humana e envolve tudo aquilo que nos é dado: dois braços, duas pernas, que nos torna bípede, situação que não é de qualquer espécie animal. Mãos que nos facultam movimento. Portanto, pertencemos a uma espécie diferente das demais; temos um cérebro tão flexível que permite o nosso desenvolvimento, que depende da oferta do ambiente.

A ontogênese abarca o desenvolvimento de um indivíduo, de uma determinada espécie, seguindo o ciclo natural biológi- 
co: nasce, se desenvolve, reproduz e morre. A sociogênese é a história da cultura onde o sujeito está inserido e o quanto essa cultura interfere no funcionamento psicológico dele. Nesse plano genético, a cultura ganha tamanha significação que funciona como um alargador das potencialidades humanas. Por exemplo, o homem tem a capacidade nata do uso da pinça, mas esse movimento tem um limite de precisão e entra aí a potencialidade da sua raça que lhe possibilita criar mecanismo por intermédio de outo instrumento - como a tecnologia para afinar essa precisão.

Outro fator que a sociogênese diferencia as espécies: entendê-la a partir da filogênese, no sentido do ciclo da espécie que é dado; a criança nasce, se desenvolve, cresce, entra nas diferentes fases da vida (adolescência, fase adulta, velhice), mas os conceitos e formas no qual essas fases são compreendidas dependem da cultura na qual está inserida.

Dentro de suas condições biológicas o ser humano pode ser visto de diferentes maneiras, dependendo da cultura. A criança só andará quando estiver pronta para tal, adquirirá a fala ao ter condição para isso e também quando a interação com o outro lhe possibilitar; mas a cultura a que pertence determinará a partir de qual idade essa criança terá independência de ir à escola sozinho e sem a necessidade de um adulto acompanhando.

\section{DIVERSIDADE CULTURAL}

Cultura diferencia enormemente os costumes. No Japão, as crianças desde cedo vão à escola sem o acompanhamento do adulto, geralmente andando em grupo de infantes de diferentes idades; naquele entendimento isso é natural, portanto também torna-se natural uma criança cuidar da outra. Já no Brasil, por questões da nossa erudição, em face do perigo de andar sozinho por causa da violência a criança ganha essa independência mais tardiamente, o que interfere na forma de desenvolvimento diferencial de outras culturas. Entrando no plano genético da microgênese (a própria palavra "micro" diz respeito a um foco 
bem definido), considera-se que cada fenômeno psicológico tem a sua própria história. Embora tenha o foco definido, este não é estabelecido, diferentemente do ontogênese e filogênese em que é dado, determinado de certa forma. Na microgênese considera-se o percurso da criança entre um não saber e o saber. E então quando consideramos o percurso da criança significa que a construção é singular de cada pessoa e da heterogeneidade dos seres humanos.

Voltando à história das crianças japonesas, consideramos num primeiro momento que a cultura nipônica, numa ampla visão, direciona a criança a determinadas experiências e influências culturais diferentes da cultura brasileira. Mas ainda assim dentre a garotada oriental, cada uma tem o seu percurso e a sua particularidade. Podemos dizer que entre a criança não saber o caminho da escola e saber o caminho, existe uma história de aprendizagem que é de cada uma. Dependeu do outro que a acompanhou nesse percurso, das considerações; um chama mais a atenção para o caminho, para não se perder, o outro para os perigos ao atravessar a rua, outro para as características encontradas no caminho.Assim como tem quem dê maior foco às questões preventivas, preparando a criança para enfrentar dias de chuva, calor, o tempo do percurso, outros deixarão que a garotada aprenda pela experiência de fato - não que a primeira não adquirirá experiência ao passar pela chuva, mas terá havido uma informação a mais que possibilitará outra experiência. E todos esses fatores vão definindo o sujeito na sua singularidade.

Todo o postulado de Vygotsky (1996) traz a ideia de que a relação do homem com o mundo não é direta, mas mediada. Essa teoria entra fortemente nas escolas, pois o professor é o maior mediador das relações das crianças com o meio, com a cultura e com as interações. Essa pode-se chamar Mediação Simbólica, que é a relação do homem com o mundo. Não como uma relação direta, mas mediada.

O guarda-chuva que a criança pode recorrer ao uso nos dias de chuva passou de mero objeto (com varetas e cabo) para 
a função de se proteger da chuva, que foi mediada por outra pessoa que deu a esse objeto tal função, simbolizando o uso para a proteção ou levá-lo consigo como forma preventiva da chuva que pode vir. E esse uso imediato (quando já está chovendo) e o uso preventivo (se chover), é devido à representação do guarda-chuva. Existe a situação da relação direta com o mundo sem a mediação. Aprendo com a experiência direta que me mostra que pegar chuva molha, e com a roupa molhada fico numa situação desconfortável. Mas pode acontecer esse fato direto sem a mediação do uso do instrumento (guarda-chuva) e então a experiência faz com que eu entenda que quando chove preciso me proteger, mesmo que com outros instrumentos (ficar num lugar coberto).

Já quando essa relação é mediada, pode-se dizer que a experiência do outro foi intermediada por algo ou alguém, prosseguindo para o nosso crescimento histórico, não sendo necessário começar do zero todas as vezes em todas as situações.

Podemos concluir, como já mencionamos, que Vygotsky (1997) traz importante contribuição ao universo escolar, especialmente pelos estudos relacionados à Psicologia ligada à Educação. Afinal, como mostrou Vygotsky (1997) até aqui, a importância da cultura desde o surgimento do sujeito na relação com o mundo. E esse é o forte papel da escola: proporcionar essa importante relação da criança com a cultura, por meio da interação afetiva, da fala, da experiência.

O professor precisa encantar as crianças, criando a necessidade, o prazer, e então a possibilidade de ter uma experiência mais rica, é maior. O professor tem esse papel de ser o criador das necessidades, como um rico caminho de proporcionar experiência.

E então, se Vygotsky (1997) defende que a necessidade impulsiona para as experiências de apropriação pela criança, entendemos que essa imposição foi gerada pelo encantamento - podemos então compreender que o afetivo e o cognitivo são inseparáveis. Vamos compreendendo pouco a pouco o papel 
afetivo na relação da aprendizagem, sendo fundamental o envolvimento do professor na relação com as crianças e com o percurso de seu aprendizado.

E a teoria histórico-cultural atesta que tudo o que somos é resultado da experiência de vida e da educação que tivemos. Portanto, os professores desenvolvem inteligência e personalidade, sendo a escola o lugar onde as crianças têm maior oportunidade de se desenvolver.

$\mathrm{Na}$ linha de raciocínio de Dewey (1938), aquele que vive uma experiência não permanece o mesmo. Então, se passamos por uma situação e aquilo não nos transformou, então não tivemos uma experiência.

Com base nessas reflexões, tem-se que o planejamento do professor de educação infantil com os campos de experiência deve ser focado no espaço, no tempo, nas relações e nas experiências. Não qualquer espaço, mas o espaço que propicie curiosidade. Essa é uma importante estratégia utilizada pelo educador, eu lhe permite incentivar a partir da possibilidade de criação, da possibilidade das múltiplas linguagens, da construção, exploração, investigação ativa, descoberta. É importante compreender que a aprendizagem pode se dar em qualquer espaço, em todos os momentos. Materiais diversos, atraentes, rico em possibilidades de exploração, de qualidade e coerência na quantidade.

E o tempo é o mais difícil, porque as lógicas constituem o nosso ser. Nós vivemos a experiência de escola e carregamos a nossa experiência em tudo o que vamos fazer. A nossa experiência de escola e de tempo é o tempo que não é o tempo da experiência. Nos apropriamos de uma ideia de tempo que não nos permite pensar que a ideia de tempo pode ser outra. Se considerarmos o tempo do relógio, não possibilitamos o tempo da experiência. É importante considerarmos que cada um tem o seu tempo, o seu ritmo, não sendo possível padronizar um tempo de atividade. Por isso é necessário cuidar para não 
escolarizarmos através do tempo, pois a escolarização rouba o tempo de experiência da criança.

Concluímos a ideia de Campos de Experiência como ideia de continuidade. As crianças têm necessidade de repetir; a criança começa, o professor acolhe e amplia

\section{REFERÊNCIAS}

BRASIL. Base Nacional Comum Curricular: Educação Infantil. Brasília: MEC/Secretaria de Educação Básica, 2017.

DEWEY, John. Experiência e Educação. Estados Unidos: Kappa Delta Pi, 1938.

OLIVEIRA-FORMOSINHO, Julia. Pedagogia(s) da infância: dialogando com o passado: construindo o futuro / Julia Oliveira Formosino, Tizuko Morchida Kishimoto, Mônica Apezzato Pinazza, organizadoras. Porto Alegre: Artmed, 2007.

OLIVEIRA, M. K. Vygotsky: aprendizado e desenvolvimento: um processo sócio-histórico. São Paulo: Scipione, 1997.

VIGOTSKI, L. S.; LURIA, A. R. Estudos sobre a história do comportamento: o macaco, o primitivo e a criança. Porto Alegre: Artes Médicas, 1996.

VIGOTSKI, L. S. A formação social da mente. São Paulo: Martins Fontes, 2007.

\section{MINICURRÍCULO}

Graduação em Psicologia e Pedagogia; especialização em Educação Infantil. É mestranda em Educação na Universidade Metodista de São Paulo (UMESP). Professora da Rede Municipal de São Bernardo do Campo (SBC). Foi coordenadora pedagógica e diretora escolar. Atualmente compõe a equipe da Educação Infantil da Secretaria de Educação de SBC. 